\title{
Applying a Hybrid MCDM Model for Six Sigma Project Selection
}

\author{
Fu-Kwun Wang, ${ }^{1}$ Chen-Hsoung Hsu, ${ }^{1}$ and Gwo-Hshiung Tzeng ${ }^{2,3}$ \\ ${ }^{1}$ Department of Industrial Management, National Taiwan University of Science and Technology, Taipei, Taiwan \\ ${ }^{2}$ Graduate Institute of Urban Planning, College of Public Affairs, National Taipei University, New Taipei, Taiwan \\ ${ }^{3}$ Institute of Management of Technology, National Chiao Tung University, Hsinchu, Taiwan \\ Correspondence should be addressed to Fu-Kwun Wang; fukwun@mail.ntust.edu.tw
}

Received 27 September 2013; Revised 17 November 2013; Accepted 19 November 2013; Published 26 February 2014

Academic Editor: Hao-Chun Lu

Copyright (C) 2014 Fu-Kwun Wang et al. This is an open access article distributed under the Creative Commons Attribution License, which permits unrestricted use, distribution, and reproduction in any medium, provided the original work is properly cited.

\begin{abstract}
Six Sigma is a project-driven methodology; the projects that provide the maximum financial benefits and other impacts to the organization must be prioritized. Project selection (PS) is a type of multiple criteria decision making (MCDM) problem. In this study, we present a hybrid MCDM model combining the decision-making trial and evaluation laboratory (DEMATEL) technique, analytic network process (ANP), and the VIKOR method to evaluate and improve Six Sigma projects for reducing performance gaps in each criterion and dimension. We consider the film printing industry of Taiwan as an empirical case. The results show that our study not only can use the best project selection, but can also be used to analyze the gaps between existing performance values and aspiration levels for improving the gaps in each dimension and criterion based on the influential network relation map.
\end{abstract}

\section{Introduction}

Six Sigma is a business strategy that seeks to identify and eliminate the causes of errors or defects, which are defined as any factors that could lead to customer dissatisfaction or failures in business processes, by focusing on outputs that are critical to customers [1-3]. Six Sigma has been widely implemented in the manufacturing sector to reduce product costs, improve quality, shorten delivery times, and increase customer satisfaction. Moreover, the Six Sigma movement is also gaining acceptance in healthcare, marketing, engineering, and financial and legal service organizations in addition to achieving major benefits in the manufacturing sector [4].

Project selection (PS) plays a vital role in the effective introduction and implementation of Six Sigma [5]. Pande et al. [6] suggested the following mantra for PS: meaningful and manageable. However, this then raises the question of how to create a meaningful and manageable PS, which will become the key issue facing the organization when conducting Six Sigma projects. This question is the essential reason for our focus on PS in Six Sigma. Also, PS is a type of multiplecriteria decision-making (MCDM) problem. Banuelas et al. [7] reported that several approaches including cost-benefit analysis, cause and effect matrices, Pareto analysis, priority indices, analytic hierarchy process (AHP), the theory of constraints (TOC), and quality function deployment (QFD) have been applied to the selection of Six Sigma projects by various organizations in the UK. Other methods such as the Balanced Scorecard method [8], data envelopment analysis (DEA) [9], a multiobjective model [10], a fuzzy-AHP with goal programming approach [11], and a hierarchical criterion evaluation process based on national quality award criteria [12] were used to select Six Sigma projects. Recently, Büyüközkan and Öztürkcan [13] developed a novel approach based on decision-making trial and evaluation laboratory (DEMATEL) technique and an analytic network process (ANP) to help logistics companies to identify and prioritize Six Sigma projects. Perçin and Kahraman [14] integrated three methods including a modified Delphi method, an AHP, and a fuzzy technique for the selection of Six Sigma projects. Tkáç and Lyócsa [15] proposed a new model based on a real options approach for evaluating Six Sigma projects, which involves the stochastic nature of project outcomes, costs, and uncertainty regarding payoffs and managerial options. Vinodh et al. [16] and Boran et al. [17] applied a fuzzy-ANP method for the selection of agile concept in a manufacturing company. Padhy and Sahu [18] proposed a two-stage methodology based on (i) real options analysis for evaluating the value of the project to improve the managerial flexibility and (ii) a zero-one integer linear programming model for 
selecting and scheduling an optimal project portfolio. Saghaei and Didehkhani [19] applied a fuzzy-weighted additive goal programming model for the evaluation and selection of Six Sigma projects. Unfortunately, these researches only provide the prioritization of Six Sigma projects. To evaluate the difference among Six Sigma projects is an important task for quality improvement. Thus, a new approach for Six Sigma project selection is needed.

We present a hybrid MCDM model to assess performance not only in ranking and selection, but also in improving and making Six Sigma project strategies for reducing gaps of each dimension/criterion to be perfect, and promote Six Sigma projects for satisfying the user needs to be number one. These processes not only can help Six Sigma project managers to understand users' wants and needs, but also can assist them with how to improve Six Sigma projects to reduce performance gaps for achieving aspiration level (see the appendix) of user satisfaction by building effective Six Sigma project strategies. An empirical study of film printing industry of Taiwan as an empirical Six Sigma projects case is illustrated to show the hybrid MCDM model for selection and improvement.

The remainder of this paper is organized as follows. Section 2 presents the PS criteria in Six Sigma. A hybrid MCDM model is developed in Section 3. Section 4 highlights the managerial implications generated by the case analysis. Finally, we offer a conclusion.

\section{Research Problem}

A project is defined as a unique set of coordinated activities, with defined starting and finishing points, which is undertaken by an individual or an organization to meet specific performance objectives within a defined schedule and within defined cost and performance parameters [20]. The objectives of a project must be clear, succinct, achievable, realistic, and measurable, with a high probability of success $[6,21]$. Antony and Fergusson [21] described how the project selection process may begin by creating a simple customer expectations-process matrix that focuses on critical business performance characteristics including quality, cost, delivery, and responsiveness.

Projects must be aligned with a strategic business plan and with organizational goals. Kendrick and Saaty [8] illustrated a set of 17 project alternatives for a manufacturing company, using AHP to determine the priorities of these projects. Project alternatives can be suggested by a bottom-up process, such as by Black or Green Belts, which are familiar with operational problems and flaws, or by a top-down process, when senior managers raise strategic issues [22]. We modified the AHP developed by Kenderick and Saaty [8] to establish a framework for project selection that includes the dimensions of feasibility, impact on customers, impact on finance, impact on operations, and impact on employees and that aligns with the strategy of the company. There are four levels of hierarchy, as well as different dimensions and criteria (see Table 1 and Figure 1).

We consider Corporation J, which has dedicated its efforts since 1993 to the development of soft packaging material for electronics and food packaging in Taiwan. Corporation $\mathrm{J}$ is one of the largest soft packaging material (SPM) manufacturers in Taiwan. The products of Corporation J include polycello and aluminum; in particular, it produces easy-peel top film and heat-sealable aluminum foil for food packaging and antistatic pouches for electronic components packaging. The quality of its products is very important to the food and electronics industries. The SPM manufacturers in Taiwan are promoting Six Sigma activities at this time. PS is the key management action required for the success of Six Sigma. There are eight alternative projects (see Table 2) that could be used to improve the manufacturing processes of Corporation J. We denote the above 6 dimensions, 17 criteria, and 8 alternatives to form a hierarchy for PS in Six Sigma as shown in Figure 1. In order to avoid "select the best among inferior projects/alternatives (i.e., pick the best apple among a barrel of rotten apples)," we compared the performance of projects and applied methods to improve the performance of dimensions and criteria in reducing the gaps remaining to achieve the aspiration levels in this study.

To assess the interinfluence of the PS criteria for the DEMATEL technique calculation, we designed a questionnaire to collect data from experts in the SPM industry and consultants for Six Sigma. These sixteen knowledge-based experts were the corporation general manager, the plant assistant general manager, the R\&D manager, the purchasing manager, the vice plant manager, and the section managers.

\section{A Hybrid MCDM Model}

A hybrid MCDM model combines the DEMATEL technique [23] with the basic concept of ANP [24] to find the influential weights of DANP and the "VIseKriterijumska Optimizacija I Kompromisno Resenje" (VIKOR, which translates as "Multicriteria Optimization and Compromise Solution") method [25] for evaluating the gaps of performance in each criterion and dimension. The DEMATEL technique was designed to determine the degrees of influential relationship matrix of the PS criteria and apply them to build supermatrix (including the unweighted and weighted supermatrices) in the basic concept of ANP. The ANP handles dependence within a dimension (inner dependence) and among different dimensions (outer dependence). The ANP is a nonlinear structure, whereas the AHP is hierarchical and linear, with goals at the top and alternatives at lower levels [26]. A hybrid MCDM model combining DEMATEL with the basic concept of ANP (referred to as DANP) has been widely applied in various fields for finding influential weights, such as innovation policy portfolios for Taiwan's silicon/semiconductor intellectual property mall, airline safety measurements, elearning evaluations, and exploring stock selection [2733]. Using the VIKOR method to rank and improve the prioritization of dimensions/criteria can be found in [34-38].

A hybrid MCDM model contains three main phases (see Figure 2): (1) constructing the influential network relation map (INRM) among the criteria by the DEMATEL technique, (2) calculating the influential weights of each criterion 
TABLE 1: The influence dimensions and criteria of comprehensive PS in Six Sigma.

\begin{tabular}{|c|c|c|}
\hline Dimensions & Influence criteria & Statements \\
\hline \multirow{3}{*}{$\begin{array}{l}\text { Strategy } \\
\left(D_{1}\right)\end{array}$} & Meaningful to organization $\left(C_{1}\right)$ & $\begin{array}{l}\text { The projects should contribute to process improvement within the } \\
\text { organization. }\end{array}$ \\
\hline & Critical to quality $\left(C_{2}\right)$ & $\begin{array}{l}\text { The selected projects should be critical for upgrading the quality of } \\
\text { the product. }\end{array}$ \\
\hline & Variable is measurable $\left(C_{3}\right)$ & $\begin{array}{l}\text { The response variables in the projects should be easily measurable for } \\
\text { implementation. }\end{array}$ \\
\hline \multirow{3}{*}{$\begin{array}{l}\text { Feasibility } \\
\left(D_{2}\right)\end{array}$} & Technical feasibility $\left(C_{4}\right)$ & $\begin{array}{l}\text { Any project in Six Sigma should be technically feasible for the } \\
\text { organization. }\end{array}$ \\
\hline & Resources are available $\left(C_{5}\right)$ & $\begin{array}{l}\text { The resources of the organization should be available to support the } \\
\text { project. }\end{array}$ \\
\hline & Time schedule $\left(C_{6}\right)$ & Project completion within four to six months should be feasible. \\
\hline \multirow{3}{*}{$\begin{array}{l}\text { Impact on customers } \\
\left(D_{3}\right)\end{array}$} & Customer satisfaction $\left(C_{7}\right)$ & $\begin{array}{l}\text { The projects for process improvement should be aimed at satisfying } \\
\text { customer needs. }\end{array}$ \\
\hline & Customer complaints $\left(C_{8}\right)$ & $\begin{array}{l}\text { The projects should reduce the complaints of the customers and } \\
\text { increase the reliability of the products. }\end{array}$ \\
\hline & New business $\left(C_{9}\right)$ & $\begin{array}{l}\text { The new project should not only consider present customers but also } \\
\text { provide benefits to new customers in the future. }\end{array}$ \\
\hline \multirow{3}{*}{$\begin{array}{l}\text { Impact on finance } \\
\left(D_{4}\right)\end{array}$} & $\operatorname{ROI}\left(C_{10}\right)$ & $\begin{array}{l}\text { Many projects in Six Sigma require the investment of equipment or } \\
\text { human power to improve the process. The return of investment (ROI) } \\
\text { of the project must be considered. }\end{array}$ \\
\hline & Cost reduction $\left(C_{11}\right)$ & $\begin{array}{l}\text { The project for process improvement should upgrade the quality of } \\
\text { products and reduce the cost of manufacturing. }\end{array}$ \\
\hline & Profit generation $\left(C_{12}\right)$ & $\begin{array}{l}\text { The projects selected should increase the generation of profit for the } \\
\text { organization. }\end{array}$ \\
\hline \multirow{3}{*}{$\begin{array}{l}\text { Impact on operations } \\
\left(D_{5}\right)\end{array}$} & Reduction in cycle time $\left(C_{13}\right)$ & $\begin{array}{l}\text { The projects for process improvement should not only improve the } \\
\text { quality of products but also reduce the cycle time of relevant } \\
\text { processes. }\end{array}$ \\
\hline & $\begin{array}{l}\text { Upgrade operational } \\
\text { performance }\left(C_{14}\right)\end{array}$ & $\begin{array}{l}\text { The projects should increase the unit time production quantity and } \\
\text { upgrade the equipment's utilization. }\end{array}$ \\
\hline & $\begin{array}{l}\text { Improved in compliance and } \\
\text { controls }\left(C_{15}\right)\end{array}$ & $\begin{array}{l}\text { The compliance and controls in operational systems should be } \\
\text { improved by discussion and communication regarding project } \\
\text { selection. }\end{array}$ \\
\hline \multirow[t]{2}{*}{$\begin{array}{l}\text { Impact on employees } \\
\left(D_{6}\right)\end{array}$} & Retaining rate $\left(C_{16}\right)$ & $\begin{array}{l}\text { The retaining rate refers to the rate at which key employees were kept } \\
\text { within the organization. The project selection in Six Sigma should } \\
\text { support employee retention for the company. }\end{array}$ \\
\hline & Improved capability $\left(C_{17}\right)$ & $\begin{array}{l}\text { Employees should be educated and trained to improve the capability } \\
\text { of manufacturing processes and the performance of the organization. }\end{array}$ \\
\hline
\end{tabular}

by using the basic concept of ANP based on the totalinfluence matrix by the DEMATEL technique, and (3) ranking and improving the prioritization of dimensions/criteria or projects through the VIKOR method for reducing gaps in each criterion and dimension to achieve the aspiration levels.

3.1. Phase I. The three steps of DEMATEL and INRM are summarized as follows.

Step 1. Calculate the direct-influence matrix A by scores. An assessment of the relationship between each criterion of mutual influence is made according to the opinions of knowledge-based experts in Six Sigma and maganers in the printing firms of Taiwan in real situation, using a scale ranging from 0 to 4 , with scores represented by natural language: "absolutely no influence (0)," "low influence (1)," "medium influence (2)," "high influence (3)," and "very high influence (4)." The knowledge-based experts are required to indicate the direct-influence by a pairwise comparision, and if they believe that criterion $i$ has an effect/influence on criterion $j$, they should indicate this by $a_{i j}$. Thus, average matrix $\mathbf{A}=\left[a_{i j}\right]_{n \times n}$ of direct relationships can be obtained as

$$
\mathbf{A}=\left[\begin{array}{ccccc}
a_{11} & \cdots & a_{1 j} & \cdots & a_{1 n} \\
\vdots & & \vdots & & \vdots \\
a_{i 1} & \cdots & a_{i j} & \cdots & a_{i n} \\
\vdots & & \vdots & & \vdots \\
a_{n 1} & \cdots & a_{n j} & \cdots & a_{n n}
\end{array}\right]
$$


TABle 2: The alternatives of PS in Six Sigma.

\begin{tabular}{|c|c|c|}
\hline Alternatives & Purposes & Statements of alternatives in Six Sigma \\
\hline (1) Decision support $\left(P_{1}\right)$ & Easy implementation of Six Sigma & $\begin{array}{l}\text { The projects implemented always need support from top } \\
\text { management. }\end{array}$ \\
\hline $\begin{array}{l}\text { (2) Improve material and } \\
\text { products inspection system } \\
\left(P_{2}\right)\end{array}$ & $\begin{array}{l}\text { Ensure the quality of materials and } \\
\text { products }\end{array}$ & $\begin{array}{l}\text { An inspection system for quality is the foundation of total } \\
\text { quality management and a key successful factor of Six Sigma. }\end{array}$ \\
\hline $\begin{array}{l}\text { (3) Operational process } \\
\text { improvement }\left(P_{3}\right)\end{array}$ & Upgrade operational performance & $\begin{array}{l}\text { Operations management techniques for the manufacturing or } \\
\text { services provided by the company should be improved. }\end{array}$ \\
\hline $\begin{array}{l}\text { (4) Training and practice of } \\
\text { employees }\left(P_{4}\right)\end{array}$ & $\begin{array}{l}\text { Promote improvement of employees' } \\
\text { abilities }\end{array}$ & $\begin{array}{l}\text { Training of employees includes projects operation and } \\
\text { management in Six Sigma. }\end{array}$ \\
\hline $\begin{array}{l}\text { (5) Upgrade supply chain } \\
\text { management }(\mathrm{SCM})\left(P_{5}\right)\end{array}$ & $\begin{array}{l}\text { Shorten lead time and improve inventory } \\
\text { control }\end{array}$ & $\begin{array}{l}\text { SCM includes material requirement planning, logistics, and } \\
\text { inventory control. }\end{array}$ \\
\hline $\begin{array}{l}\text { (6) Establish lean } \\
\text { production system }\left(P_{6}\right)\end{array}$ & Waste reduction and variability reduction & $\begin{array}{l}\text { Lean production supplies the customer with exactly what the } \\
\text { customer wants when the customer wants it, without waste, } \\
\text { through continuous improvement. }\end{array}$ \\
\hline $\begin{array}{l}\text { (7) Promote quality } \\
\text { function deployment } \\
(\mathrm{QFD})\left(P_{7}\right)\end{array}$ & $\begin{array}{l}\text { Satisfaction of the customer and } \\
\text { deployment of quality efforts }\end{array}$ & $\begin{array}{l}\text { QFD refers to both (1) determining what will satisfy the } \\
\text { customer and (2) translating those customer desires into the } \\
\text { target design. }\end{array}$ \\
\hline $\begin{array}{l}\text { (8) Invest in inspection } \\
\text { equipment and instruments } \\
\left(P_{8}\right)\end{array}$ & $\begin{array}{l}\text { Upgrade the correctness of inspection } \\
\text { results for Six Sigma } \\
\text { improvement }\end{array}$ & $\begin{array}{l}\text { The key equipment and instruments for polyester film printing } \\
\text { for the packaging industry are gas chromatographs and color } \\
\text { difference inspectors. }\end{array}$ \\
\hline
\end{tabular}

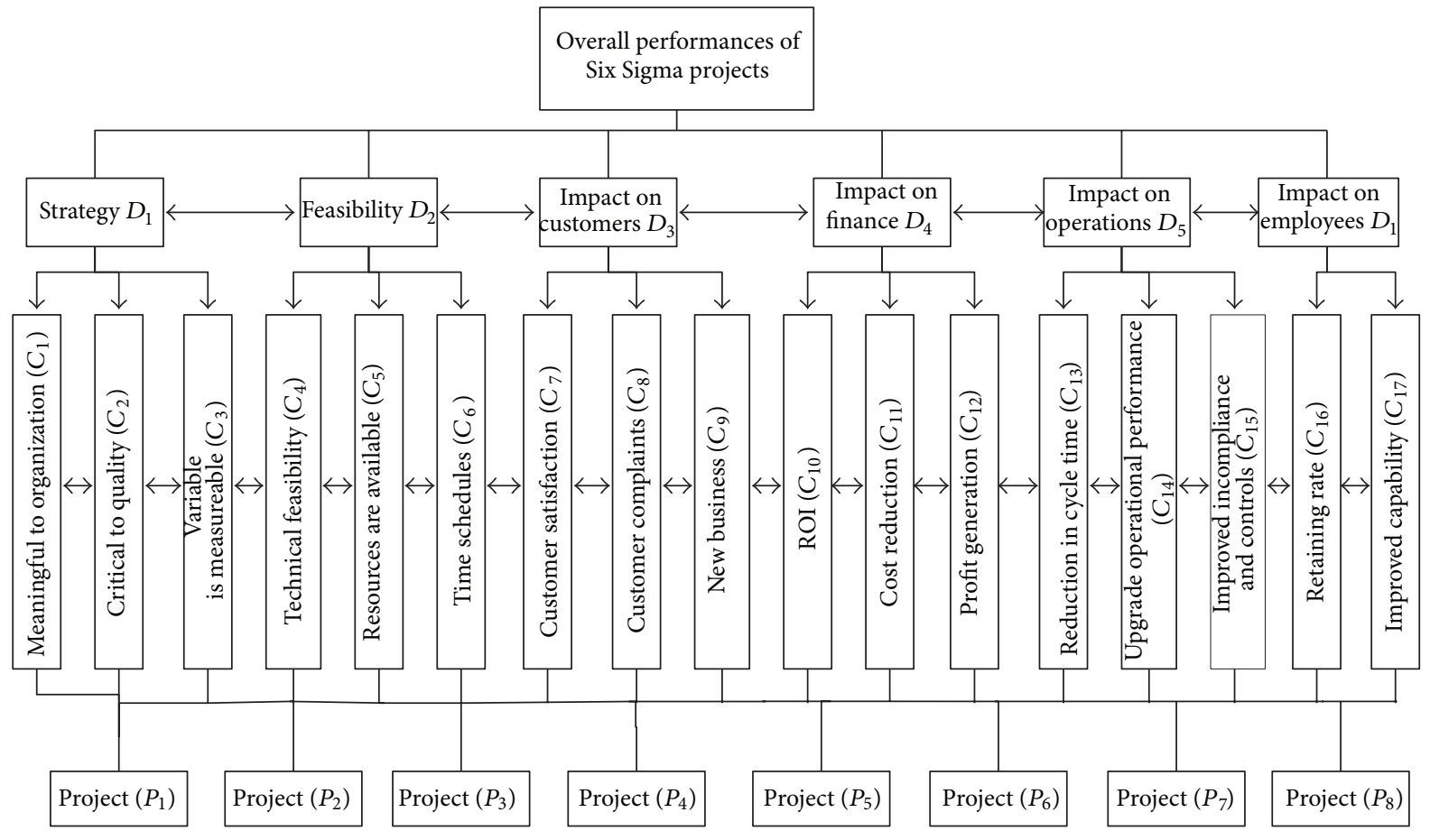

FIGURE 1: The network of project selection in Six Sigma.

Step 2. Calculate the normalized direct-influence matrix $\mathbf{X}$. The normalized direct-influence matrix $\mathbf{X}$ is derived by

$$
\mathbf{X}=z \times \mathbf{A},
$$

where $z=\min _{i, j}\left\{1 / \max _{i} \sum_{j=1}^{n} a_{i j}, 1 / \max _{j} \sum_{i=1}^{n} a_{i j}\right\}$, for all $i, j=(1,2, \ldots, n)$. Its diagonal is zero, and the maximum sum of rows or columns is one.
Step 3. Derive the total-influence matrix T. The continuous decrease in the indirect effects of problems can be determined using the powers of $\mathbf{X}$, for example, $\mathbf{X}^{2}, \mathbf{X}^{3}, \ldots, \mathbf{X}^{h}$, with $\lim _{h \rightarrow 0} \mathbf{X}^{h}=[0]_{n \times n}$, where $\mathbf{X}=\left[x_{i j}\right]_{n \times n}, 0 \leq x_{i j}<1$, $0 \leq \sum_{i} x_{i j} \leq 1,0 \leq \sum_{j} x_{i j} \leq 1$, and at least one column or one row of summation, but not every column or row, equals one; then $\lim _{\ell \rightarrow \infty} \mathbf{X}^{\ell}=[0]_{n \times n}$ can be 


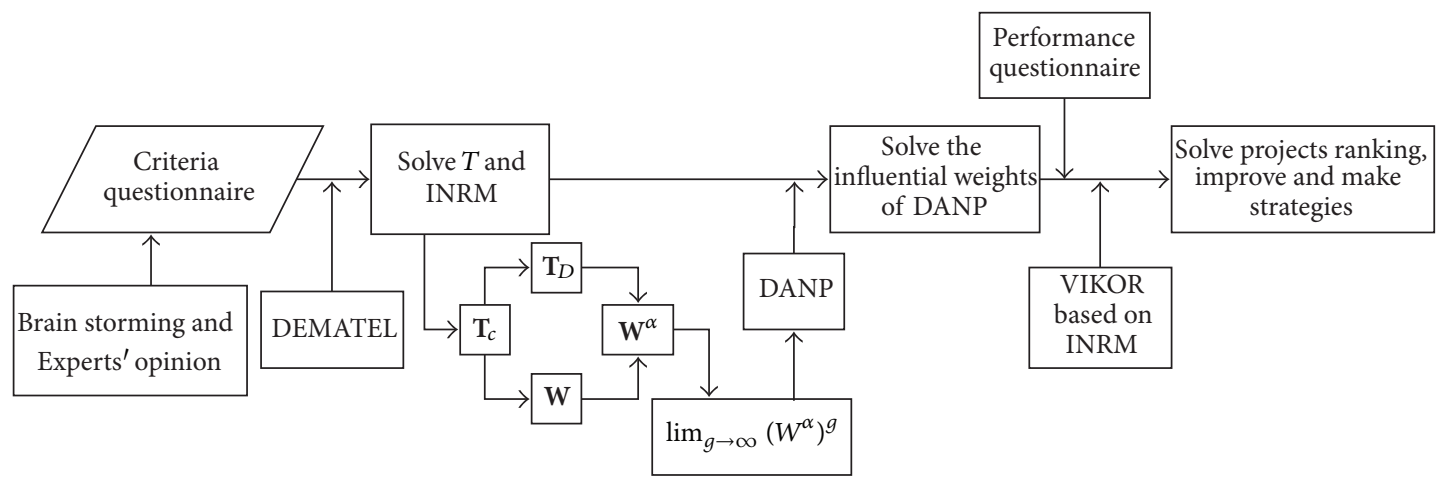

FIGURE 2: The process of a hybrid MCDM model combining DANP and VIKOR.

guaranteed. Thus, the total-influence matrix $\mathbf{T}$ is derived by

$$
\mathbf{T}=\mathbf{X}+\mathbf{X}^{2}+\cdots+\mathbf{X}^{h}=\mathbf{X}(\mathbf{I}-\mathbf{X})^{-1}
$$

where $\lim _{h \rightarrow 0} \mathbf{X}^{h}=[0]_{n \times n}$ and $\mathbf{I}$ denotes the identity matrix.

The sum of the rows and the sum of the columns of $\mathbf{T}$ are expressed separately as vector $\mathbf{r}$ and vector $\mathbf{s}$. That is, we have

$$
\begin{aligned}
& \mathbf{r}=\left[r_{i}\right]_{n \times 1}=\left[\sum_{j=1}^{n} t_{i j}\right]_{n \times 1}, \\
& \mathbf{s}=\left[s_{j}\right]_{n \times 1}=\left[\sum_{i=1}^{n} t_{i j}\right]_{1 \times n}^{\prime},
\end{aligned}
$$

where the superscript ' denotes the transpose. Also, $r_{i}$ shows the sum of the direct and indirect effects of criteria $i$ on the other criteria and $s_{j}$ shows the sum of the direct and indirect effects that criteria $j$ has received from the other criteria. Furthermore, $\left(r_{i}+s_{i}\right)$ shows the degree that the criteria $i$ plays in the problem, and the difference $\left(r_{i}-s_{i}\right)$ shows the net effect that criteria $i$ contributes to the problem. If $\left(r_{i}-s_{i}\right)$ is positive, then criteria $i$ is affecting other criteria, and if $\left(r_{i}-s_{i}\right)$ is negative, then criteria $i$ is being influenced by other criteria. These results are used to generate the INRM. The INRM can provide ideas for improvement.

3.2. Phase II. The five steps of DANP influential weights are described as follows.

Step 1. Find the normalized matrix $\mathbf{T}_{c}^{\alpha}$ by using dimensions. After normalizing the total-influence matrix $\mathbf{T}_{c}$ by dimensions, we can obtain a new normalized matrix $\mathbf{T}_{c}^{\alpha}$ by dimensions and is given by

$$
\begin{aligned}
& \begin{array}{lll}
D_{1} & D_{j} & D_{n}
\end{array}
\end{aligned}
$$

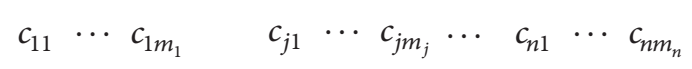

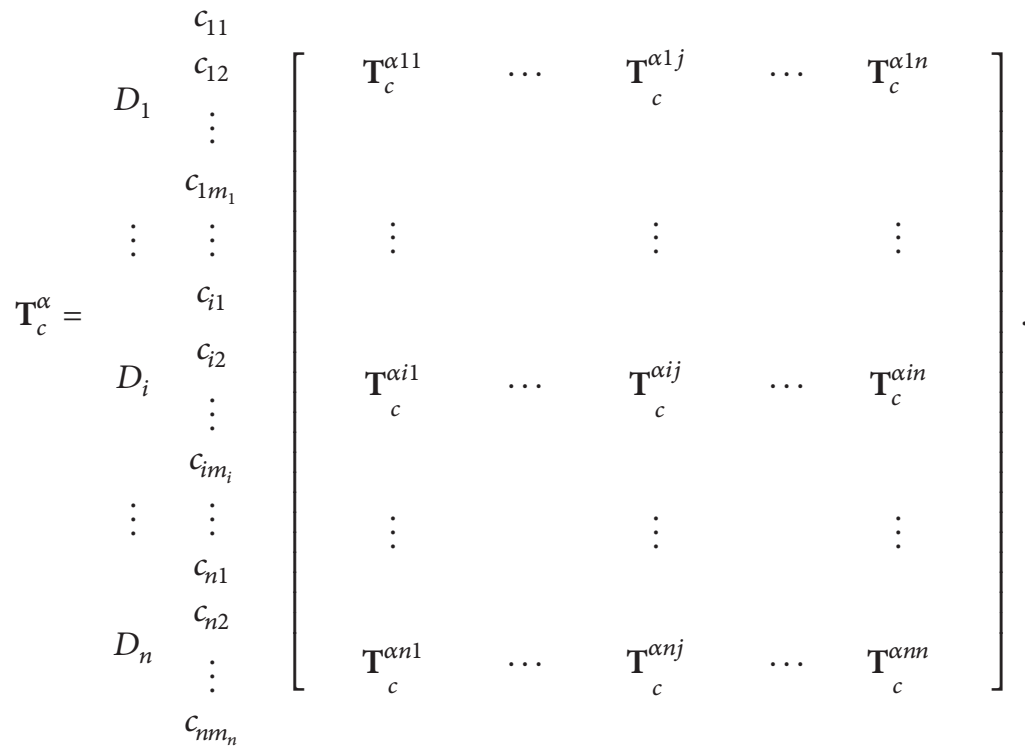


For instance the normalization $\mathbf{T}_{c}^{\alpha 11}$ is shown as (5) and (6).

$$
\begin{aligned}
& \text { Consider the following: } \\
& d_{c i}^{11}=\sum_{j=1}^{m_{1}} t_{c i j}^{11}, \quad i=1,2, \ldots, m_{1}, \\
& \mathbf{T}_{c}^{\alpha 11}=\left[\begin{array}{ccccc}
\frac{t_{c 11}^{11}}{d_{c 1}^{11}} & \cdots & \frac{t_{c 1 j}^{11}}{d_{c 1}^{11}} & \cdots & \frac{t_{c 1 m_{1}}^{11}}{d_{c 1}^{11}} \\
\vdots & & \vdots & & \vdots \\
\frac{t_{c i 1}^{11}}{d_{c i}^{11}} & \cdots & \frac{t_{c i j}^{11}}{d_{c i}^{11}} & \cdots & \frac{t_{c i m_{1}}^{11}}{d_{c i}^{11}} \\
\vdots & & \vdots & & \vdots \\
\frac{t_{c m_{1} 1}^{11}}{d_{c m_{1}}^{11}} & \cdots & \frac{t_{c m_{1} j}^{11}}{d_{c m_{1}}^{11}} & \cdots & \frac{t_{c m_{1} m_{1}}^{11}}{d_{c m_{1}}^{11}}
\end{array}\right]
\end{aligned}
$$

$$
=\left[\begin{array}{ccccc}
t_{c 11}^{\alpha 11} & \cdots & t_{c 1 j}^{\alpha 11} & \cdots & t_{c 1 m_{1}}^{\alpha 11} \\
\vdots & & \vdots & & \vdots \\
t_{c i 1}^{\alpha 11} & \cdots & t_{c i j}^{\alpha 11} & \cdots & t_{c i m_{1}}^{\alpha 11} \\
\vdots & & \vdots & & \vdots \\
t_{c m_{1} 1}^{\alpha 11} & \cdots & t_{c m_{1} j}^{\alpha 11} & \cdots & t_{c m_{1} m_{1}}^{\alpha 11}
\end{array}\right] .
$$

Step 2. Find the unweighted supermatrix W. Let the totalinfluence matrix match and be filled into the interdependence dimensions. It is based on transposing the normalized influence matrix $\mathbf{T}_{c}^{\alpha}$ by using dimensions, that is, $\mathbf{W}=\left(\mathbf{T}_{c}^{\alpha}\right)^{\prime}$, and is derived by

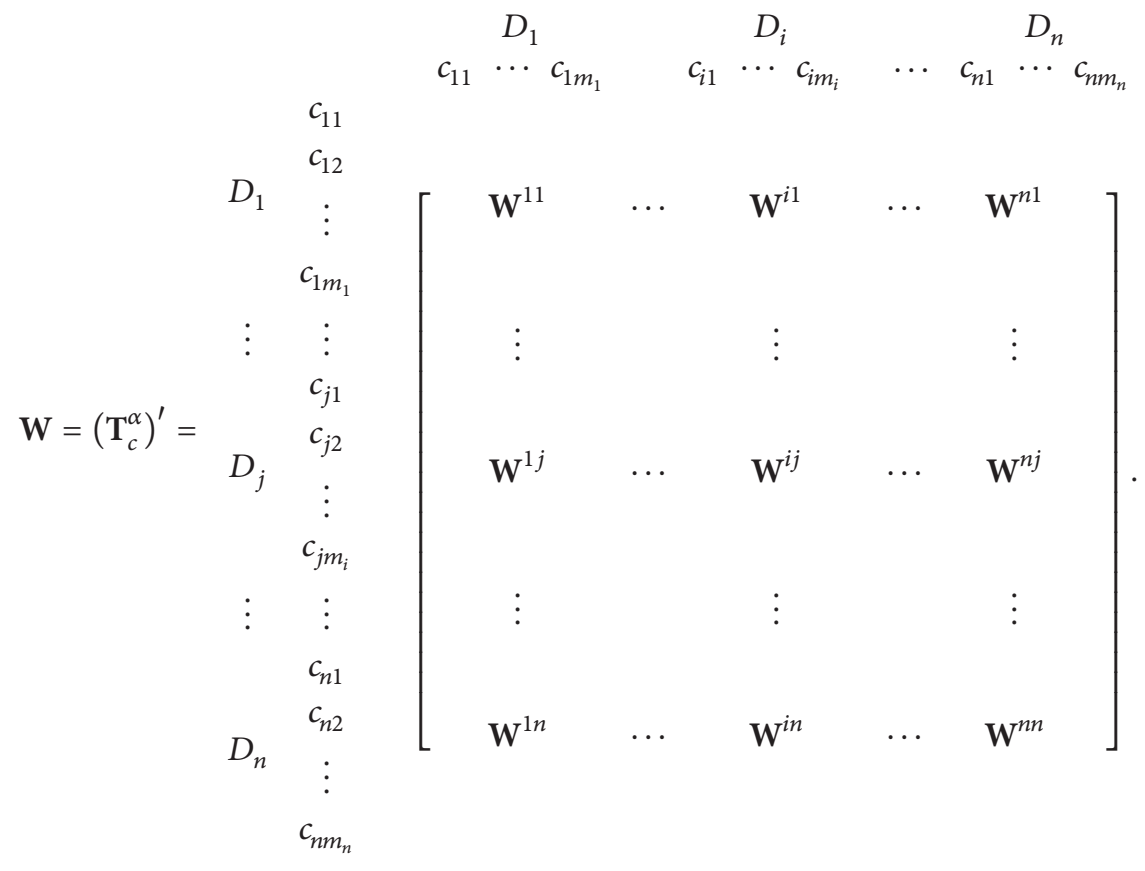

Step 3. Obtain the normalized supermatrix $\mathbf{T}_{D}^{\alpha}$ by dimensions. Total-influencematrix $\mathbf{T}_{D}$ is obtained by

$$
\mathbf{T}_{D}=\left[\begin{array}{ccccc}
t_{D}^{11} & \cdots & t_{D}^{1 j} & \cdots & t_{D}^{1 n} \\
\vdots & & \vdots & & \vdots \\
t_{D}^{i 1} & \cdots & t_{D}^{i j} & \cdots & t_{D}^{i n} \\
\vdots & & \vdots & & \vdots \\
t_{D}^{n 1} & \cdots & t_{D}^{n j} & \cdots & t_{D}^{n n}
\end{array}\right] .
$$

Each column of total-influence matrix $\mathbf{T}_{D}$ by dimensions can be summed for normalization. Then we normalize the total-influence matrix $\mathbf{T}_{D}$ and obtain a new normalized matrix $\mathbf{T}_{D}^{\alpha}$. A new normalized matrix $\mathbf{T}_{D}^{\alpha}$ is derived by

$$
\mathbf{T}_{D}^{\alpha}=\left[\begin{array}{ccccc}
\frac{t_{D}^{11}}{d_{1}} & \cdots & \frac{t_{D}^{1 j}}{d_{1}} & \cdots & \frac{t_{D}^{1 n}}{d_{1}} \\
\vdots & & \vdots & & \vdots \\
\frac{t_{D}^{i 1}}{d_{i}} & \cdots & \frac{t_{D}^{i j}}{d_{i}} & \cdots & \frac{t_{D}^{i n}}{d_{i}} \\
\vdots & & \vdots & & \vdots \\
\frac{t_{D}^{n 1}}{d_{n}} & \cdots & \frac{t_{D}^{n j}}{d_{n}} & \cdots & \frac{t_{D}^{n n}}{d_{n}}
\end{array}\right]
$$




$$
=\left[\begin{array}{ccccc}
t_{D}^{\alpha 11} & \cdots & t_{D}^{\alpha 1 j} & \cdots & t_{D}^{\alpha 1 n} \\
\vdots & & \vdots & & \vdots \\
t_{D}^{\alpha i 1} & \cdots & t_{D}^{\alpha i j} & \cdots & t_{D}^{\alpha i n} \\
\vdots & & \vdots & & \vdots \\
t_{D}^{\alpha n 1} & \cdots & t_{D}^{\alpha n j} & \cdots & t_{D}^{\alpha n n}
\end{array}\right],
$$

where $t_{D}^{\alpha i j}=t_{D}^{i j} / d_{i}$ and $d_{i}=\sum_{j=1}^{n} t_{D}^{i j}$.

Step 4. Calculate the weighted supermatrix. The weighted supermatrix $\mathbf{W}^{\alpha}$ is derived by

$$
\begin{aligned}
\mathbf{W}^{\alpha}= & \mathbf{T}_{D}^{\alpha} \mathbf{W} \\
= & {\left[\begin{array}{ccccc}
t_{D}^{\alpha 11} \times \mathbf{W}^{11} & \cdots & t_{D}^{\alpha i 1} \times \mathbf{W}^{i 1} & \cdots & t_{D}^{\alpha n 1} \times \mathbf{W}^{n 1} \\
\vdots & & \vdots & & \vdots \\
t_{D}^{\alpha 1 j} \times \mathbf{W}^{1 j} & \cdots & t_{D}^{\alpha i j} \times \mathbf{W}^{i j} & \cdots & t_{D}^{\alpha n j} \times \mathbf{W}^{n j} \\
\vdots & & \vdots & & \vdots \\
t_{D}^{\alpha 1 n} \times \mathbf{W}^{1 n} & \cdots & t_{D}^{\alpha i n} \times \mathbf{W}^{i n} & \cdots & t_{D}^{\alpha n n} \times \mathbf{W}^{n n}
\end{array}\right] . }
\end{aligned}
$$

Step 5. Limit the weighted supermatrix by raising it to a sufficiently large power $k$, until the supermatrix has converged and become a long-term stable supermatrix to obtain the global vector weights, called the DANP influential weights, such that $\lim _{g \rightarrow \infty}\left(\mathbf{W}^{\alpha}\right)^{g}$, where $g$ represents any number of powers when $g \rightarrow \infty$.

3.3. Phase III. The development of the VIKOR method began with the following form of $L_{p}$ metric:

$$
L_{k}^{p}=\left\{\sum_{j=1}^{n}\left[\frac{w_{j}\left(\left|f_{j}^{*}-f_{k j}\right|\right)}{\left(\left|f_{j}^{*}-f_{j}^{-}\right|\right)}\right]^{p}\right\}^{1 / p},
$$

where $f_{k j}$ is the performance score of the $j$ th criterion on $k$ th alternative, $w_{j}$ is the influential weight of the $j$ th criterion from DANP, and $n$ is the number of criteria and $1 \leq p \leq \infty$ [39]. Two measures $L_{k}^{p=1}$ (as $S_{k}$ for minimal average gap or degree of regret) and $L_{k}^{p=\infty}$ (as $Q_{k}$ for priority improvement) are established as

$$
\begin{gathered}
S_{k}=L_{k}^{p=1}=\sum_{j=1}^{n}\left[\frac{w_{j}\left(\left|f_{j}^{*}-f_{k j}\right|\right)}{\left(\left|f_{j}^{*}-f_{j}^{-}\right|\right)}\right], \\
Q_{k}=L_{k}^{p=\infty}=\max _{j}\left\{\frac{\left(\left|f_{j}^{*}-f_{k j}\right|\right)}{\left(\left|f_{j}^{*}-f_{j}^{-}\right|\right)} \mid j=1,2, \ldots, n\right\} .
\end{gathered}
$$

The compromise solution $\min _{k} L_{k}^{p}$ shows the synthesized gap to be minimized, which will be selected or improved such that its gap values in each criterion and dimension will be improved for the closest to the aspiration level. Regarding INRM, the group utility is emphasized when $p$ is small (such as $p=1$ ); in contrast, if $p$ grows toward infinity, the individual maximal gaps attain greater importance for priority improvement in each dimension or criterion. Consequently, $\min _{k} S_{k}$ stresses the maximum group utility; however, $\min _{k} Q_{k}$ focuses on selecting the minimal value from the maximum individual gaps for priority improvement.

The VIKOR method in this study has four steps.

Step 1. Obtain an aspired/desired and tolerable level. We calculated the best $f_{j}^{*}$ values (the aspiration level) and the worst $f_{j}^{-}$values (the tolerable level) of all criterion functions, $j=1,2, \ldots, n$. In traditional approach we suppose that the $j$ th function denotes benefits: $f_{j}^{*}=\max _{k} f_{k j}$ and $f_{j}^{-}=\min _{k} f_{k j}$, but in this research we use the performance scores from 1 to 9 (very poor $\leftarrow 1,2, \ldots, 8,9 \rightarrow$ the best) in questionnaires (see the appendix), so the aspiration level can be set at 9 score and the worst value at 1 score. Therefore, in this research, we set $f_{j}^{*}=9$ as the aspiration level and $f_{j}^{-}=1$ as the worst value, which differs from traditional approach. This approach can avoid "choose the best among inferior choices/options/alternatives (i.e., avoid pick the best apple among a barrel of rotten apples)." Furthermore, an original rating matrix can be converted into the following matrix:

$$
r_{k j}=\frac{\left(\left|f_{j}^{*}-f_{k j}\right|\right)}{\left(\left|f_{j}^{*}-f_{j}^{-}\right|\right)}
$$

Step 2. Calculate the mean of group utility and maximal regret. The values can be computed by $S_{k}=\sum_{j=1}^{n} w_{j} r_{k j}$ (the synthesized gap for all of the criteria) and $Q_{k}=\max _{j}\left\{r_{k j} \mid\right.$ $j=1,2, \ldots, n\}$ (the maximal gap in criterion $k$ for priority improvement), respectively.

Step 3. Rank or improve the alternatives for a compromise solution. We order the alternatives from the calculated values, which are obtained as

$$
R_{k}=\frac{v\left(S_{k}-S^{*}\right)}{\left(S^{-}-S^{*}\right)}+\frac{(1-v)\left(Q_{k}-Q^{*}\right)}{\left(Q^{-}-Q^{*}\right)}, \quad \forall k=1,2, \ldots, m,
$$

where $S^{*}=\min _{i} S_{i}$ or $S^{*}=0$ (when all of the criteria have been achieved to the aspiration level); $S^{-}=\max _{i} S_{i}$ or $S^{-}=1$ (in the worst case); $Q^{*}=\min _{i} Q_{i}$ or can be set as $Q^{*}=0$; $Q^{-}=\max _{i} Q_{i}$ or $Q^{-}=1$; and $v$ is presented as the weight of the strategy of the maximum group utility. Conversely, $1-v$ is the weight of individual regret. When $S^{*}=0, S^{-}=1, Q^{*}=0$, and $Q^{-}=1$, we can rewrite (15) as

$$
R_{k}=v S_{k}+(1-v) Q_{k}
$$

Step 4. Decreasing order of the values of $S_{k}, Q_{k}$, and $R_{k}$, then, we can use them for a compromise solution for all alternatives.

\section{Results and Discussions}

The significant confidence of the 16 experts' group consensus in the questionnaires, the mean of sample gap equals only $1.795 \%$; that is, the significant confidence is obtained as 
TABle 3: The initial influence matrix $\mathbf{A}$ for criteria.

\begin{tabular}{|c|c|c|c|c|c|c|c|c|c|c|c|c|c|c|c|c|c|}
\hline Crite & $C_{1}$ & $C_{2}$ & $C_{3}$ & $C_{4}$ & $C_{5}$ & $C_{6}$ & $C_{7}$ & $C_{8}$ & $C_{9}$ & $C_{10}$ & $C_{11}$ & $C_{12}$ & $C_{13}$ & $C_{14}$ & $C_{15}$ & $C_{16}$ & $C_{17}$ \\
\hline$C_{1}$ & 0.00 & 3.38 & 3.00 & 3.13 & 3.31 & 3.06 & 3.19 & 3.13 & 2.94 & 3.00 & 3.06 & 3.06 & 3.00 & 3.25 & 2.56 & 2.63 & 2.88 \\
\hline$C_{2}$ & 3.25 & .00 & 3.00 & 3.19 & 3.13 & 3.13 & 3.56 & 3.44 & 2.56 & 2.81 & 2.69 & 3.00 & 2.69 & 3.06 & 2.56 & 2.50 & 2.81 \\
\hline$C_{3}$ & 2.81 & 3.06 & 0.00 & 2.88 & 2.81 & 2.81 & 2.81 & 2.56 & 2.38 & 2.69 & 2.69 & 2.75 & 2.94 & 3.00 & 2.31 & 2.13 & 2.19 \\
\hline$C_{4}$ & 2.88 & 3.25 & 3.19 & 0.00 & 3.00 & 3.06 & 3.06 & 2.88 & 2.75 & 3.31 & 2.88 & 3.25 & 3.13 & 3.31 & 2.44 & 2.19 & 2.69 \\
\hline$C_{5}$ & 3.00 & 3.06 & 2.94 & 3.19 & 0.00 & 3.13 & 2.88 & 2.75 & 2.44 & 3.06 & 3.13 & 3.13 & 3.00 & 3.13 & 2.38 & 2.69 & 2.56 \\
\hline$C_{6}$ & 2.63 & 2.88 & 3.00 & 3.00 & 2.88 & 0.00 & 3.06 & 2.75 & 2.06 & 2.69 & 2.94 & 2.88 & 3.00 & 3.06 & 2.31 & 2.50 & 2.50 \\
\hline$C_{7}$ & 3.38 & 3.38 & 3.00 & 3.19 & 3.06 & 3.06 & 0.00 & 3.38 & 2.81 & 2.94 & 2.63 & 3.06 & 2.38 & 2.81 & 2.69 & 2.94 & 2.63 \\
\hline$C_{8}$ & 3.31 & 3.56 & 2.94 & 3.13 & 2.88 & 2.88 & 3.44 & 0.00 & 2.50 & 2.63 & 2.44 & 2.69 & 2.38 & 2.50 & 2.75 & 2.81 & 2.63 \\
\hline$C_{9}$ & 3.19 & 2.56 & 2.69 & 3.19 & 3.13 & 2.56 & 3.19 & 2.56 & 0.00 & 3.13 & 2.63 & 3.13 & 2.38 & 2.63 & 2.69 & 2.44 & 2.69 \\
\hline$C_{10}$ & 2.94 & 3.06 & 3.19 & 3.25 & 3.38 & 2.81 & 3.25 & 2.94 & 3.00 & 0.00 & 3.00 & 3.25 & 3.19 & 3.31 & 2.56 & 2.69 & 2.94 \\
\hline$C_{11}$ & 3.00 & 3.00 & 3.06 & 3.19 & 3. & 3.06 & S & 3 & 1 & 0 & 0.00 & 1 & 2.75 & 9 & 2.75 & .56 & 2.81 \\
\hline$C_{12}$ & 3.13 & 3.25 & 2.94 & 3.44 & 3.38 & 3.13 & 3.00 & 3.00 & 13 & 3.25 & 3.44 & 0.00 & 3.06 & 3.25 & 2.81 & 3.06 & 2.81 \\
\hline$C_{13}$ & 3.00 & 2.75 & 3.13 & 3.31 & 3.13 & 3.31 & 2.94 & 2.81 & 2.63 & 2.81 & 3.25 & 3.19 & 0.00 & 2.94 & 2.75 & 2.44 & 2.94 \\
\hline$C_{14}$ & 3.13 & 3.31 & 3.00 & 3.25 & 3.25 & 3.31 & 3.25 & 3.00 & 2.63 & 2.94 & 2.94 & 3.13 & 3.31 & 0.00 & 2.69 & 2.94 & 3.06 \\
\hline$C_{15}$ & 2.69 & 2.88 & 2.50 & 2.75 & 2.69 & 2.63 & 2.88 & 2.81 & 2.50 & 2.56 & 2.50 & 2.56 & 2.75 & 2.81 & 0.00 & 3.00 & 2.75 \\
\hline$C_{16}$ & 2.50 & 2.75 & 2.50 & 2.38 & 2.44 & 2.13 & 2.81 & 2.81 & 2.25 & 2.63 & 2.69 & 2.63 & 2.69 & 2.88 & 3.00 & 0.00 & 2.81 \\
\hline$C_{17}$ & 2.88 & 3.06 & 2.63 & 3.06 & 2.88 & 2.69 & 3.13 & 2.94 & 2.94 & 2.88 & 2.88 & 3.06 & 3.31 & 3.50 & 2.88 & 2.69 & 0.00 \\
\hline
\end{tabular}

Note: the mean of sample gap $=(1 / n(n-1)) \sum_{i=1}^{n} \sum_{j=1}^{n}\left(\left|a_{i j}^{p}-a_{i j}^{p-1}\right| / a_{i j}^{p}\right) \times 100 \%=1.795 \%<5 \%$, where $n$ is the number of criteria and $p$ is the sample of 16 experts.

TABLE 4: The total-influence matrix $\mathbf{T}_{D}$ and influence given/received for dimensions.

\begin{tabular}{|c|c|c|c|c|c|c|c|c|c|c|c|c|}
\hline $\mathbf{T}_{D}$ & $D_{1}$ & $D_{2}$ & $D_{3}$ & $D_{4}$ & $D_{5}$ & $D_{6}$ & $r_{i}$ & Dimensions & $r_{i}$ & $s_{i}$ & $r_{i}+s_{i}$ & $r_{i}-s_{i}$ \\
\hline$D_{1}$ & 0.78 & 0.80 & 0.77 & 0.78 & 0.76 & 0.71 & 4.60 & Strategy $\left(D_{1}\right)$ & 4.60 & 4.76 & 9.36 & -0.16 \\
\hline$D_{2}$ & 0.79 & 0.78 & 0.76 & 0.77 & 0.75 & 0.71 & 4.57 & Feasibility $\left(D_{2}\right)$ & 4.57 & 4.80 & 9.36 & -0.23 \\
\hline$D_{3}$ & 0.79 & 0.79 & 0.75 & 0.77 & 0.75 & 0.71 & 4.55 & Impact on customers $\left(D_{3}\right)$ & 4.55 & 4.61 & 9.16 & -0.05 \\
\hline$D_{4}$ & 0.84 & 0.85 & 0.81 & 0.80 & 0.80 & 0.75 & 4.85 & Impact on finance $\left(D_{4}\right)$ & 4.85 & 4.65 & 9.49 & 0.20 \\
\hline$D_{5}$ & 0.80 & 0.81 & 0.77 & 0.78 & 0.74 & 0.72 & 4.62 & Impact on operations $\left(D_{5}\right)$ & 4.62 & 4.54 & 9.16 & 0.09 \\
\hline$D_{6}$ & 0.77 & 0.77 & 0.74 & 0.75 & 0.74 & 0.67 & 4.43 & Impact on employees $\left(D_{6}\right)$ & 4.43 & 4.28 & 8.71 & 0.16 \\
\hline$s_{i}$ & 4.76 & 4.80 & 4.61 & 4.65 & 4.54 & 4.28 & & & & & & \\
\hline
\end{tabular}

98.205\% which is greater than 95\% (see note in Table 3). There are eight projects that were submitted by the Six Sigma team of Corporation J. Utilizing the aforementioned six dimensions and 17 criteria, we evaluated the performance of each project based on the opinions of sixteen knowledgebased experts and the consultants in SPM manufacturing and the Six Sigma technique. We evaluated performances on a scale of 1 to 9 , with 1 indicating very poor performance (i.e., $f_{j}^{-}=1$ is called the worst value) and 9 indicating the best performance (i.e., $f_{j}^{*}=9$ is called the aspiration level). Then, we used the average performance scores of each project and applied the VIKOR method to obtain the performances and the gaps to the aspiration levels of the alternative projects.

Using (2) and (3), the normalized direct-influence matrix and the total-influence of $\mathbf{T}_{C}$ and $\mathbf{T}_{D}$ can be easily derived. The INRM was constructed using the vectors $\mathbf{r}$ and $\mathbf{s}$ fromthe total direct-influence matrix $\mathbf{T}_{D}$ (see Table 4 ). The sum of influences given and received on criteria is shown in Table 5. In addition, the INRM maps are shown in Figure 3.

In Figure 3, we found that six dimensions are influenced by each other such as strategy $\left(D_{1}\right)$ will be influenced by impact on customers $\left(D_{3}\right)$, impact on finance $\left(D_{4}\right)$, and impact on operations $\left(D_{5}\right)$; feasibility $\left(D_{2}\right)$ will be influenced by strategy $\left(D_{1}\right)$, impact on customers $\left(D_{3}\right)$, impact on finance $\left(D_{4}\right)$, and impact on employees $\left(D_{6}\right)$. These influential relationships will help the Six Sigma team to perform the decision-making. To increase the feasibility of projects, the first step is to improve their impact on finance. In particular, the Six Sigma team can first refer to $D_{4}$ in Figure 3 to improve the contribution of ROI $\left(C_{10}\right)$ for the project. For the same reason, the projects need the support of the top management of strategy $\left(D_{1}\right)$, but strategy $\left(D_{1}\right)$ depended on the impact on finance $\left(D_{4}\right)$, impact on customers $\left(D_{3}\right)$, and impact on employees $\left(D_{6}\right)$. In conclusion, the managers of Six Sigma can refer to the INRM to prioritize their improvements to the dimensions and criteria in PS.

We used the DANP method to obtain the influential weights and priorities of the dimensions and criteria in the empirical case of Corporation J. The performances and the gaps to the aspiration levels of the alternative projects are shown in Table 6 . We found that the priority in global weights of the first dimension is feasibility $\left(D_{2}\right)$, followed by strategy $\left(D_{1}\right)$, impact on finance $\left(D_{4}\right)$, impact on customers 

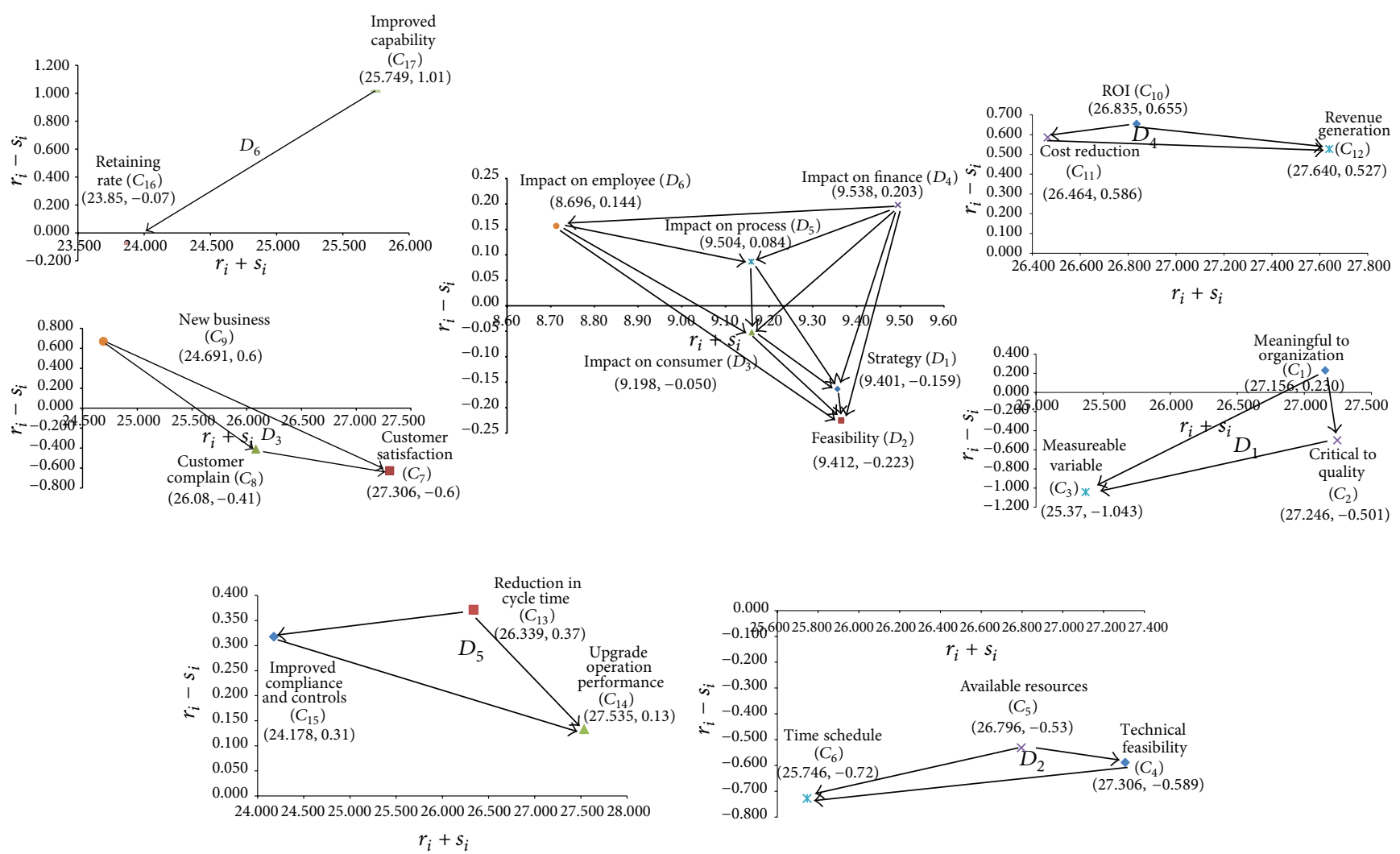

FIGURE 3: The influential network relation maps.

TABLE 5: The sum of influences given and received on criteria.

\begin{tabular}{lcccc}
\hline Criteria & $r_{i}$ & $s_{i}$ & $r_{i}+s_{i}$ & $r_{i}-s_{i}$ \\
\hline Meaningful to organization $\left(C_{1}\right)$ & 13.69 & 13.46 & 27.16 & 27.25 \\
Critical to quality $\left(C_{2}\right)$ & 13.37 & 13.87 & 25.37 & -0.50 \\
Variable is measurable $\left(C_{3}\right)$ & 12.16 & 13.21 & 27.31 & -1.04 \\
Technical feasibility $\left(C_{4}\right)$ & 13.36 & 13.95 & 26.80 & -0.59 \\
Resources are available $\left(C_{5}\right)$ & 13.13 & 13.66 & 25.75 & -0.53 \\
Time schedule $\left(C_{6}\right)$ & 12.51 & 13.24 & 27.31 & -0.73 \\
Customer satisfaction $\left(C_{7}\right)$ & 13.34 & 13.97 & -0.63 \\
Customer complaints $\left(C_{8}\right)$ & 12.84 & 13.25 & 24.69 & -0.41 \\
New business $\left(C_{9}\right)$ & 12.68 & 12.01 & 26.84 & 26.46 \\
ROI $\left(C_{10}\right)$ & 13.74 & 13.09 & 27.64 & 0.67 \\
Cost reduction $\left(C_{11}\right)$ & 13.53 & 12.94 & 26.34 \\
Profit generation $\left(C_{12}\right)$ & 14.08 & 13.56 & 27.53 \\
Reduction in cycle time $\left(C_{13}\right)$ & 13.36 & 12.98 & 0.65 \\
Upgrade operational performance $\left(C_{14}\right)$ & 13.83 & 13.70 & 24.18 \\
Improved in compliance and controls $\left(C_{15}\right)$ & 12.25 & 11.93 & 23.85 \\
Retaining rate $\left(C_{16}\right)$ & 11.89 & 11.96 & 12.37 & 0.53 \\
Improved capability $\left(C_{17}\right)$ & 13.38 & & 0.37 \\
\hline
\end{tabular}

$\left(D_{3}\right)$, impact on operations $\left(D_{5}\right)$, and impact on employees $\left(D_{6}\right)$, in that order. In addition, we extended the priority of the criteria in each dimension from the local weights in Table 6. For instance, feasibility $\left(D_{2}\right)$ is the first priority in dimensions of global weights; when extended to the local weight dimensions, however, we know that the technical feasibility $\left(C_{4}\right)$ will be the first priority of feasibility $\left(D_{2}\right)$. All of these local and global weights will be helpful in selecting and improving the best alternatives in MCDM problems with the VIKOR method. 


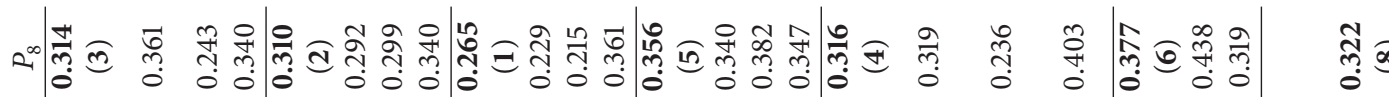

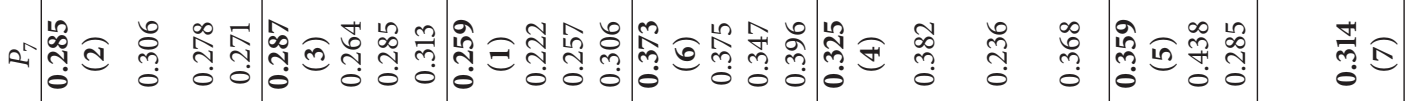

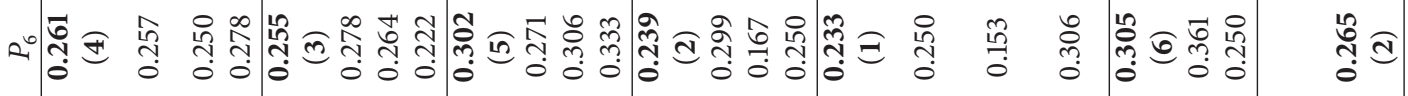

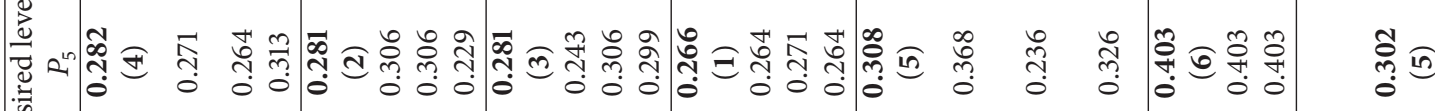

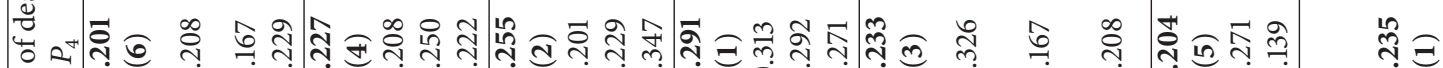

चि

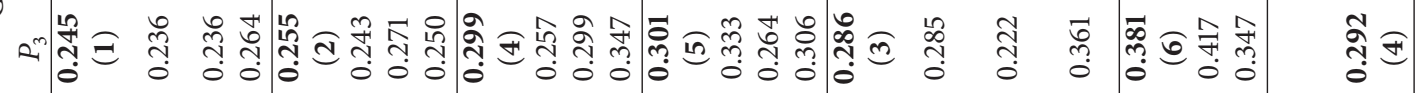

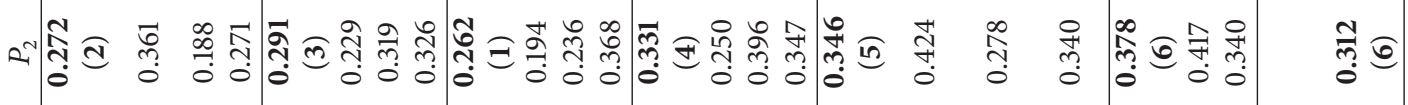

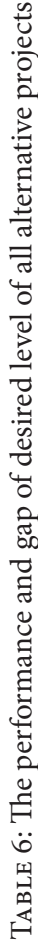

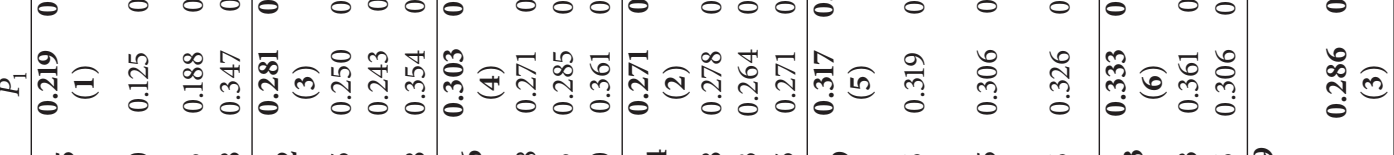

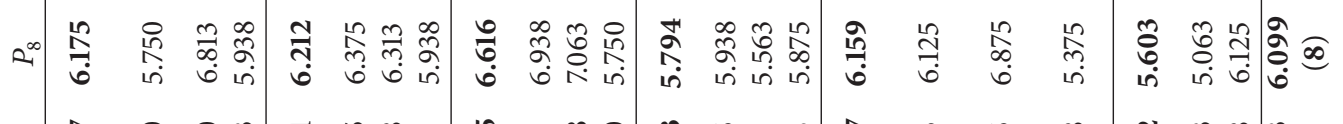

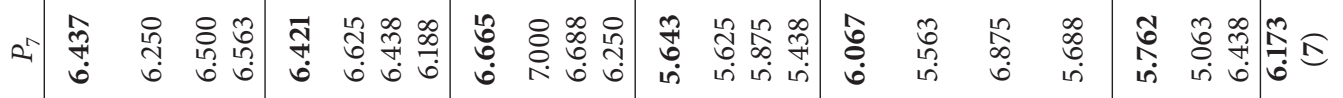

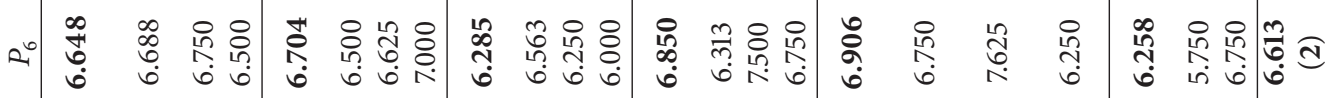

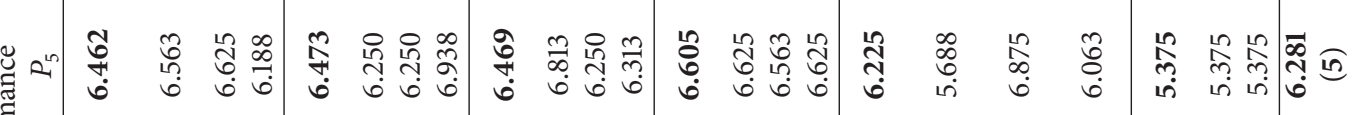

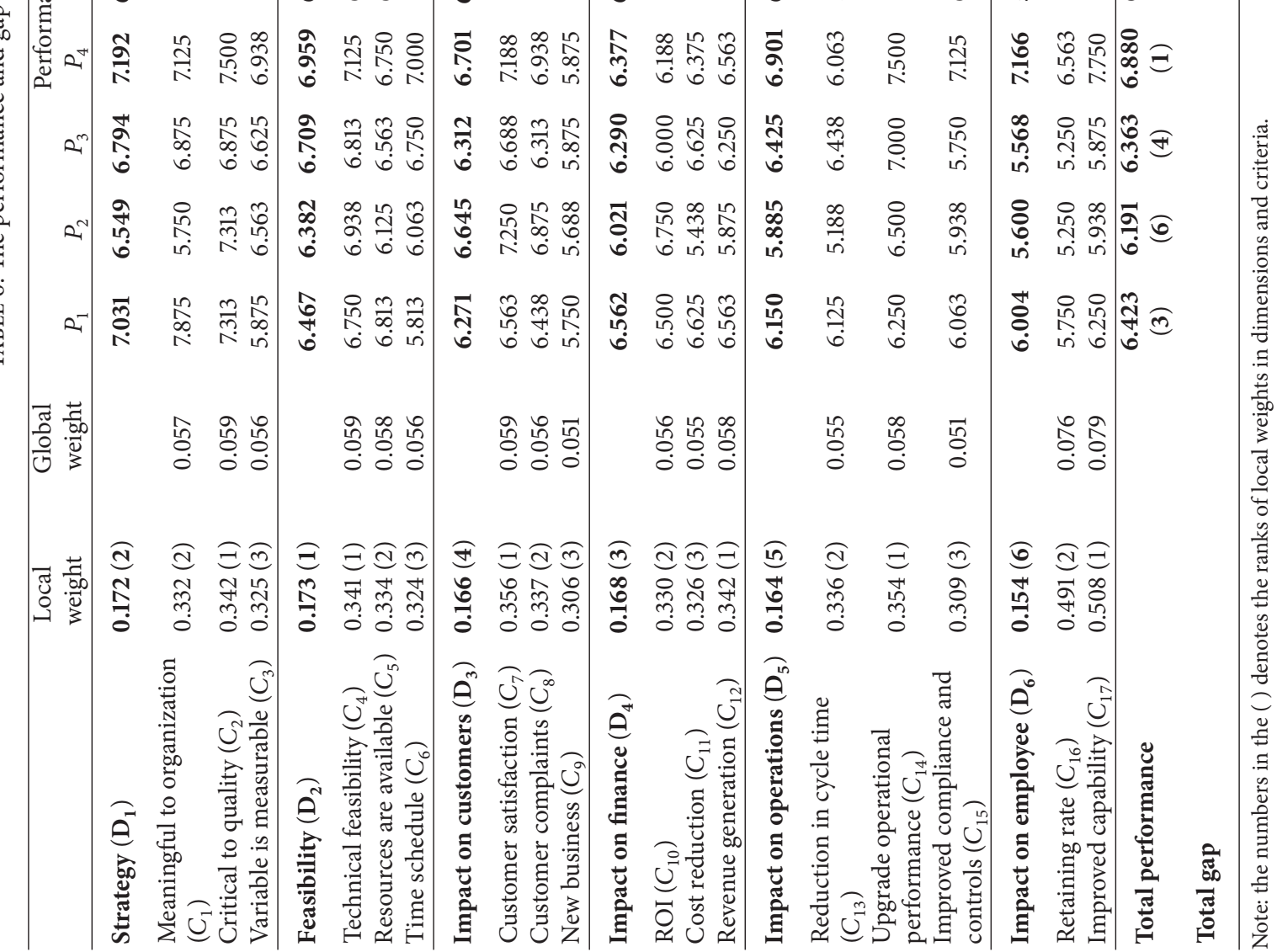


In analyzing the empirical case of an SPM manufacturing company using a hybrid MCDM model, we successfully obtained the influential relationship matrix as well as the map of the PS dimensions and criteria in interdependent and feedback problems. We also, compared the performance of projects and obtained how to improve the performance of dimensions and criteria in reducing the gaps remaining to achieve the aspiration levels. We conclude the following.

(1) Based on the DANP method, the global influential weights and local influential weights of the dimensions and criteria can be obtained, and then by combining DANP with the VIKOR method the average scores of the projects from project $P_{1}$ to project $P_{8}$, in performance, are 6.423, 6.191, $6.363,6.880,6.281,6.613,6.173$, and 6.099, respectively (see Table 6). We found that project $P_{4}$ has the best performance among the eight projects, with a score of 6.88 , which means that the training and practice of employees $\left(P_{4}\right)$ are the first priority for the Six Sigma projects. In accordance with the scores of the projects, the subsequent priorities are the establishment of a lean production system $\left(P_{6}\right)$, decision support $\left(P_{1}\right)$, operational process improvement $\left(P_{3}\right)$, the upgrading of supply chain management $\left(P_{5}\right)$, the improvement of the material/products inspection system $\left(P_{3}\right)$, the promotion of quality function deployment $\left(P_{7}\right)$, and the investment in inspection equipment/instruments $\left(P_{8}\right)$.

(2) The traditional PS approach is to rank the project alternatives and then only select the best of the project. Our proposed model can not only use the best project selection but can also analyze which gaps in the dimensions and criteria should be the priorities for improvement. From the perspective of the VIKOR method, project $P_{4}$ is the first priority of Six Sigma projects in this SPM case; however the gap of 0.292 in this case should also be reduced to zero (the aspiration level, no gap) questions regarding how to minimize this gap as much as possible. We can propose several improvement strategies and suggestions for the managers of Six Sigma to promote the project's performance based on the INRM. For example, in Table 6 and Figure 3, the largest gap to the aspiration level in project $P_{4}$ is 0.291 (impact on finance, $D_{4}$ ); next is 0.255 (impact on customers, $D_{3}$ ), then 0.233 (impact on operations, $D_{5}$ ), 0.227 (feasibility, $D_{2}$ ), 0.204 (impact on employees, $D_{6}$ ), and 0.201 (strategy, $D_{1}$ ). This information can assist managers in improving the project performance of Six Sigma to reduce the gaps in question and achieve the aspiration level quickly and directly.

\section{Conclusion}

PS is one of the most critical and challenging activities faced by companies, and selecting the right project in Six Sigma is a major factor in its early success and long-term acceptance within any organization. Based on the definition of a project, the objectives must be clear, succinct, achievable, realistic, and measurable, with a high probability of success. We developed dimensions and criteria that align with the strategy of a SPM manufacturing company to evaluate and select Six Sigma projects.
We present a hybrid MCDM model combining the influential weights of DANP with the VIKOR method for an empirical case in the SPM industry to integrate each criterion performance into each dimension and overall performance. So a DANP model can overcome the problems of interdependence and feedback among dimensions and criteria in the real world. Based on the global and local influential weights of DANP and combined with VIKOR's calculation (see Table 6), mangers can make decisions which take into account the integration of performances and the improvement of the gaps to the aspiration level of each dimension. In this case study, we not only designated the prioritization of the projects in the order of training and practice of employees (P4) $\rightarrow$ establish lean production system (P6) $\rightarrow$ decision support $(\mathrm{P} 1) \rightarrow$ operational process improvement $(\mathrm{P} 3) \rightarrow$ upgrade supply chain management $(\mathrm{P} 5) \rightarrow$ improve material and products inspection system $(\mathrm{P} 2) \rightarrow$ promote quality function deployment (P7) and invest in inspection equipment and instrument (P8), but we also determined how to improve the gaps to achieve the aspiration level of performance in each project, from low value to high value.

To reduce the gaps and achieve the aspiration level (zero gaps) in the best or most suitable areas, other methods, such as the dominance-based rough set approach (DRSA) and PROMETHEE III, should be addressed in the future studies. In order to deal with uncertainty or fuzziness in the decision making process, a fuzzy-ANP can be considered in our proposed model.

\section{Appendix}

Liou and Tzeng [40] found that the traditional MCDM ignored some important new concepts and trends (some assumptions limit/defects) for solving actual problems in the real world. First, the traditional model assumes that the criteria are independent and hierarchical in structure; however, criteria are often interdependent in real-world problems; because "Statistics and Economics are unrealistic in the real world," DEMATEL technique can be used to find the influence matrix and build an INRM for solving this problem. Second, the relative good solution from the existing alternatives is replaced by the aspiration levels. Note: Herbert A. Simon, in his lecture given in Stockholm upon receiving the Nobel Prize in Economics, 1978; the Scottish word "satisficing" (=satisfying) has been revived to denote problem solving and decision making that sets an aspiration level, searches until an alternative is found that is satisfactory by the aspiration level criterion, and selects that alternative [41]. In this research, if $f_{j}^{*}$ is the aspiration level and $f_{j}^{-}$ is the worst value, we use the performance scores from 0 to 10 (very dissatisfaction $\leftarrow 0,1,2, \ldots, 9,10 \rightarrow$ very satisfaction) in questionnaires, so the aspiration level can be set at 10 score (i.e., $f_{j}^{*}=10$ ) and the worst value at zero score (i.e., $f_{j}^{-}=0$ ); this approach can avoid "Choose the best among inferior/choices/alternatives," that is, avoid "Pick the best apple among a barrel of rotten apples." Third, the trends have shifted from how to carry out the "ranking" or "selection" of the most preferable alternatives, to how to 
"improve" their performances based on INRM, because "we need a systematic approach to problem-solving; instead of addressing the systems of the problem, we need to identify the sources of the problem [42]." These ideas and concepts can offer major contributions in this type of research problem.

\section{Conflict of Interests}

The authors declare that they have no conflict of interests.

\section{Acknowledgments}

The authors gratefully acknowledge assistant editor and two reviewers of this paper who helped clarify and improve this presentation.

\section{References}

[1] J. Antony and R. Banuelas, "Key ingredients for the effective implementation of six sigma program," Measuring Business Excellence, vol. 6, no. 4, pp. 20-27, 2002.

[2] J. Antony, "Some pros and cons of six sigma: an academic perspective," The TQM Magazine, vol. 16, no. 4, pp. 303-306, 2004.

[3] R. D. Snee, "Six sigma: the evolution of 100 years of business improvement methodology," International Journal of Six Sigma and Competitive Advantage, vol. 1, no. 1, pp. 4-20, 2004.

[4] A. Y. T. Szeto and A. H. C. Tsang, "Antecedents to successful implementation of six sigma," International Journal of Six Sigma and Competitive Advantage, vol. 1, no. 3, pp. 307-322, 2005.

[5] Y. H. Kwak and F. T. Anbari, "Benefits, obstacles, and future of six sigma approach," Technovation, vol. 26, no. 5-6, pp. 708-715, 2006.

[6] P. S. Pande, R. P. Neuman, and R. R. Cavanagh, The Six Sigma Way, McGraw-Hill, New York, NY, USA, 2000.

[7] R. Banuelas, C. Tennant, I. Tuersley, and S. Tang, "Selection of six sigma projects in the UK," The TQM Magazine, vol. 18, no. 5, pp. 514-527, 2006.

[8] J. D. Kendrick and D. Saaty, "Use analytic hierarchy process for project selection," Six Sigma Forum Magazine, vol. 6, no. 4, pp. 22-29, 2007.

[9] U. D. Kumar, H. Saranga, J. E. Ramírez-Márquez, and D. Nowicki, "Six sigma project selection using data envelopment analysis," The TQM Magazine, vol. 19, no. 5, pp. 419-441, 2007.

[10] G. Hu, L. Wang, S. Fetch, and B. Bidanda, "A multi-objective model for project portfolio selection to implement lean and six sigma concepts," International Journal of Production Research, vol. 46, no. 23, pp. 6611-6625, 2008.

[11] C. Kahraman and G. Büyüközkan, "A combined fuzzy AHP and fuzzy goal programming approach for effective six-sigma project selection," Journal of Multiple-Valued Logic and Soft Computing, vol. 14, no. 6, pp. 599-615, 2008.

[12] T. Yang and C.-H. Hsieh, "Six-Sigma project selection using national quality award criteria and Delphi fuzzy multiple criteria decision-making method," Expert Systems with Applications, vol. 36, no. 4, pp. 7594-7603, 2009.

[13] G. Büyüközkan and D. Öztürkcan, "An integrated analytic approach for six sigma project selection," Expert Systems with Applications, vol. 37, no. 8, pp. 5835-5847, 2010.
[14] S. Perçin and C. Kahraman, "An integrated fuzzy multi-criteria decision-making approach for six sigma project selection," International Journal of Computational Intelligence Systems, vol. 3, no. 5, pp. 610-621, 2010.

[15] M. Tkáç and Š. Lyócsa, "On the evaluation of six sigma projects," Quality and Reliability Engineering International, vol. 26, no. 1, pp. 115-124, 2010.

[16] S. Vinodh, S. G. Gautham, R. Anesh Ramiya, and D. Rajanayagam, "Application of fuzzy analytic network process for agile concept selection in a manufacturing organisation," International Journal of Production Research, vol. 48, no. 24, pp. 7243-7264, 2010.

[17] S. Boran, H. R. Yazgan, and K. Goztepe, "A fuzzy ANP-based approach for prioritising projects: a six sigma case study," International Journal of Six Sigma and Competitive Advantage, vol. 6, no. 3, pp. 133-155, 2011.

[18] R. K. Padhy and S. Sahu, "A real option based six sigma project evaluation and selection model," International Journal of Project Management, vol. 29, no. 8, pp. 1091-1102, 2011.

[19] A. Saghaei and H. Didehkhani, "Developing an integrated model for the evaluation and selection of six sigma projects based on ANFIS and fuzzy goal programming," Expert Systems with Applications, vol. 38, no. 1, pp. 721-728, 2011.

[20] M. Kumar, J. Antony, and B. R. Cho, "Project selection and its impact on the successful deployment of six sigma," Business Process Management Journal, vol. 15, no. 5, pp. 669-686, 2009.

[21] J. Antony and C. Fergusson, "Six sigma in the software industry: results from a pilot study," Managerial Auditing Journal, vol. 19, no. 8, pp. 1025-1032, 2004.

[22] J. Van den Heuvel, R. J. M. M. Does, A. J. J. C. Bogers, and M. Berg, "Implementing six sigma in the Netherlands," Joint Commission Journal on Quality and Patient Safety, vol. 32, no. 7, pp. 393-399, 2006.

[23] E. Fontela and A. Gabus, "The DEMATEL observe," Battelle Institute, Geneva, Switzerland, 1976.

[24] T. L. Saaty, Decision Making with Dependence and Feedback: The Analytic Network Process, RWS, Pittsburgh, Pa, USA, 1996.

[25] S. Opricovic and G.-H. Tzeng, "Multicriteria planning of postearthquake sustainable reconstruction," Computer-Aided Civil and Infrastructure Engineering, vol. 17, no. 3, pp. 211-220, 2002.

[26] T. L. Saaty, "Rank from comparisons and from ratings in the analytic hierarchy/network processes," European Journal of Operational Research, vol. 168, no. 2, pp. 557-570, 2006.

[27] C.-Y. Huang, J. Z. Shyu, and G.-H. Tzeng, "Reconfiguring the innovation policy portfolios for Taiwan's SIP mall industry," Technovation, vol. 27, no. 12, pp. 744-765, 2007.

[28] F. Jin, P. Liu, and X. Zhang, "The evaluation study of human resources based on intuitionistic fuzzy set and TOPSIS method," Journal of Information and Computational Science, vol. 4, no. 3, pp. 1023-1028, 2007.

[29] J. J. H. Liou, G.-H. Tzeng, and H.-C. Chang, "Airline safety measurement using a hybrid model," Journal of Air Transport Management, vol. 13, no. 4, pp. 243-249, 2007.

[30] G.-H. Tzeng, C.-H. Chiang, and C.-W. Li, "Evaluating intertwined effects in e-learning programs: a novel hybrid MCDM model based on factor analysis and DEMATEL," Expert Systems with Applications, vol. 32, no. 4, pp. 1028-1044, 2007.

[31] J. J. H. Liou, L. Yen, and G.-H. Tzeng, "Building an effective safety management system for airlines," Journal of Air Transport Management, vol. 14, no. 1, pp. 20-26, 2008. 
[32] W.-S. Lee, G.-H. Tzeng, J.-L. Guan, K.-T. Chien, and J.-M. Huang, "Combined MCDM techniques for exploring stock selection based on Gordon model," Expert Systems with Applications, vol. 36, no. 3, part 2, pp. 6421-6430, 2009.

[33] L. Pei-de, "A novel method for hybrid multiple attribute decision making," Knowledge-Based Systems, vol. 22, no. 5, pp. 388-391, 2009.

[34] J. J. H. Liou, C.-Y. Tsai, R.-H. Lin, and G.-H. Tzeng, "A modified VIKOR multiple-criteria decision method for improving domestic airlines service quality," Journal of Air Transport Management, vol. 17, no. 2, pp. 57-61, 2011.

[35] P. Liu and X. Zhang, "Research on the supplier selection of a supply chain based on entropy weight and improved ELECTREIII method," International Journal of Production Research, vol. 49, no. 3, pp. 637-646, 2011.

[36] C.-H. Hsu, F.-K. Wang, and G.-H. Tzeng, "The best vendor selection for conducting the recycled material based on a hybrid MCDM model combining DANP with VIKOR," Resources, Conservation and Recycling, vol. 66, no. 1, pp. 95-111, 2012.

[37] C.-H. Liu, G.-H. Tzeng, and M.-H. Lee, "Improving tourism policy implementation-the use of hybrid MCDM models," Tourism Management, vol. 33, no. 2, pp. 239-488, 2012.

[38] P. Liu and X. Wu, "A competency evaluation method of human resources managers based on multi-granularity linguistic variables and VIKOR method," Technological and Economic Development of Economy, vol. 18, no. 4, pp. 696-710, 2012.

[39] S. Opricovic and G.-H. Tzeng, "Compromise solution by MCDM methods: a comparative analysis of VIKOR and TOPSIS," European Journal of Operational Research, vol. 156, no. 2, pp. 445-455, 2004.

[40] J. H. Liou and G. H. Tzeng, "Comments on multiple criteria decision making (MCDM) methods in economics: an overview," Technological and Economic Development of Economy, vol. 18, no. 4, pp. 672-695, 2012.

[41] H. A. Simon, "A behavioral model of rational choice," The Quarterly Journal of Economics, vol. 69, no. 1, pp. 99-118, 1955.

[42] J. H. Liou, "New concepts and trends of MCDM for tomorrowin honor of professor Gwo-Hshiung Tzeng on the occasion of his 70th birthday," Technological and Economic Development of Economy, vol. 19, no. 2, pp. 367-375, 2013. 


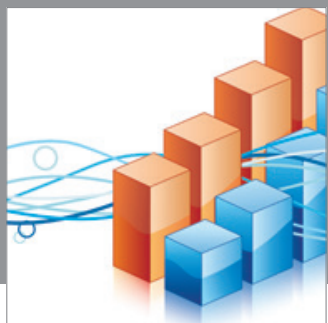

Advances in

Operations Research

mansans

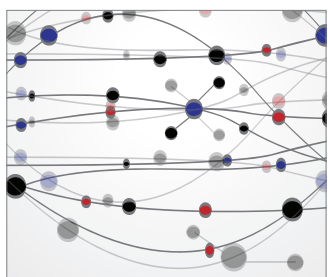

The Scientific World Journal
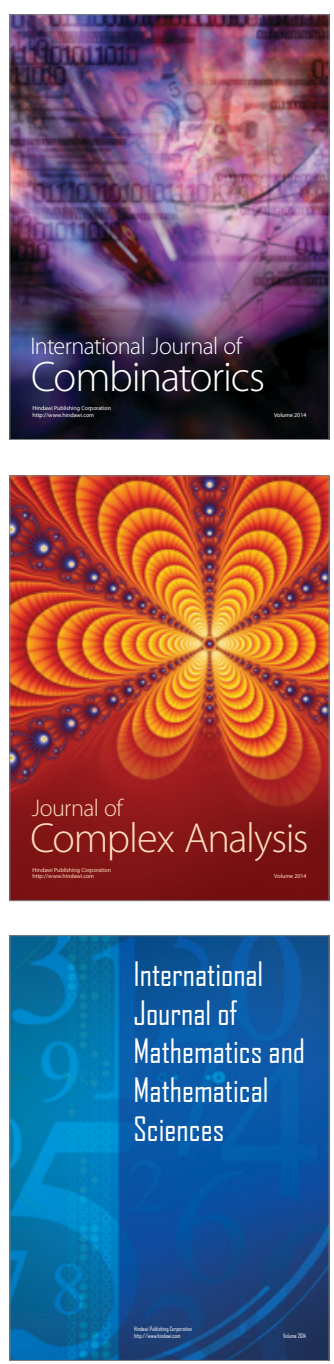
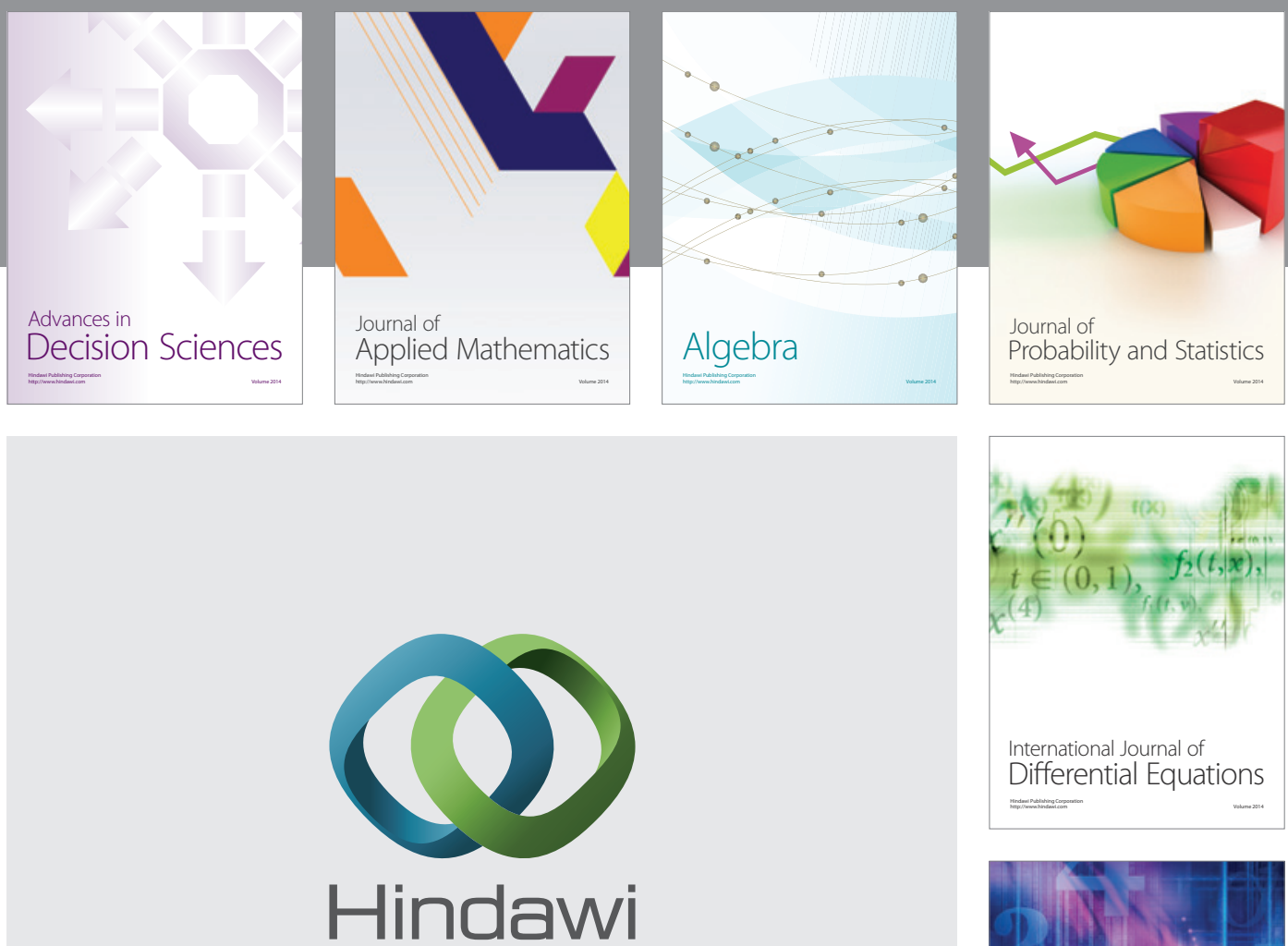

Submit your manuscripts at http://www.hindawi.com
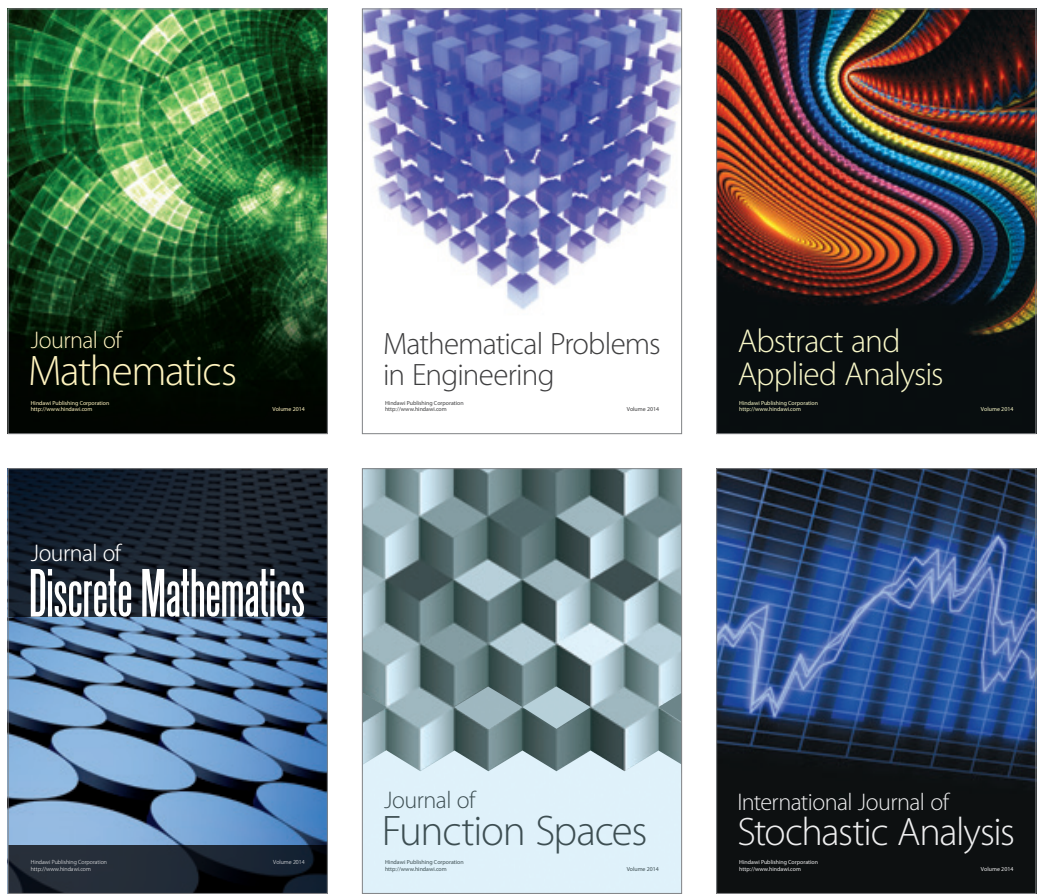

Journal of

Function Spaces

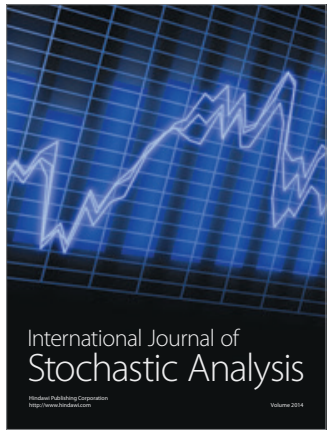

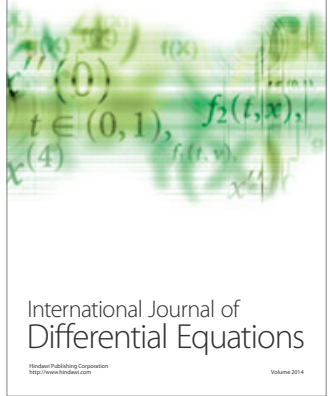
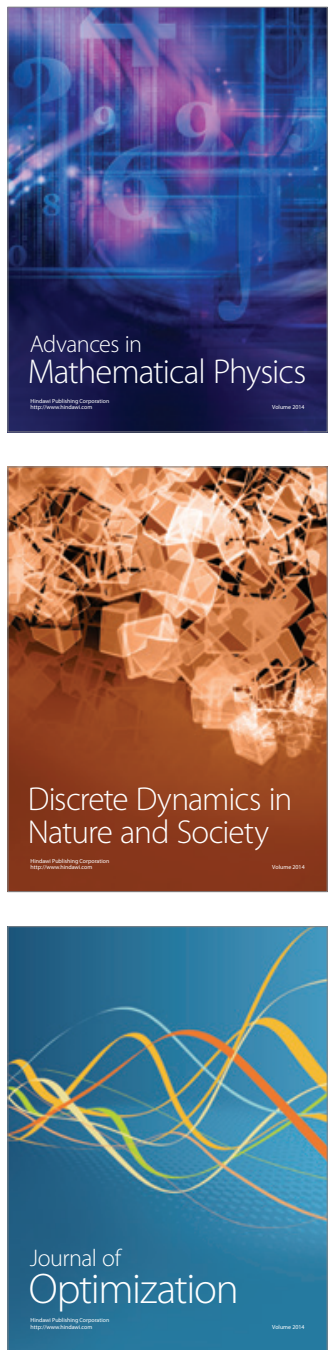